Sonic Scope: New Approaches to Audiovisual Culture

\title{
Alexander Jackson - Lost in the Gaze
}

\author{
Alexander Jackson
}

Published on: Feb 15, 2021

DOI: $10.21428 / 66 f 840 a 4.260318 \mathrm{ca}$

License: Creative Commons Attribution 4.0 International License (CC-BY 4.0). 


\section{Lost in the Gaze}

Alexander Jackson, Goldsmiths, University of London

Stuck in the temporal sinkhole of plague-time, in early November of 2020 I found myself transfixed by the Safdie brothers' video for experimental/electronic musician Oneohtrix Point Never's single "Lost But Never Alone," watching it near constantly for a seemingly indeterminate length of time. 1 Captivated by its ambitious and, at times, chaotic weaving together of different visual worlds, as well as its ability to elude simple categorisation and explanation along the lines of a retromaniac nostalgia or (forgive me) hauntology, the video lodged itself firmly in my psyche.

\section{Visit the web version of this article to view interactive content.}

Oneohtrix Point Never, "Oneohtrix Point Never - Lost But Never Alone (Official Video)," November 12, 2020, https://www.youtube.com/watch?v=6iKPkxfljBY.

Accompanying OPN, aka Daniel Lopatin, is a haze-refracted collage of often horrifying and uncanny encounters with the Other. It centres on an imaginary network television sitcom family and the discovery of their son's anachronistic iPhone, fragments of cult 1983 slasher horror Curtains (whose antagonist wears a grotesque, decrepit mask), and heart-rending footage from the final reunion of 59year-old chimpanzee, Mama, and her long-time friend and caretaker, Dutch zoologist Jan van Hooff.

The video's interstitial moments feature Lopatin performing, sandwiched within the montage. As if to drive home the theme of spectacle out of time, and the texture and interfaces of (analogue) media, the heavily filtered, Vaseline-smeared camera lens segues from monitor screen to Lopatin and back, leaving the artist trapped in Night Flight liminality.

A psychoanalytically-charged powerplay between father and son constitutes the work's denouement -if a piece of montage film can even be said to have such a thing - with the troublesome iPhone acting as both objet petit a for the son (if not the device itself, then the endless access to unattainable desirenetworks it facilitates; is constantly losing oneself in the feed a form of jouissance?) and through its destruction, a symbolic castration for the father. In response, the son retreats to his room and arms himself with the ultimate teenage phallic symbol-an angular, bright white Warlock guitar-and shreds the track's closing solo. 
Staying with this psychoanalytic perspective, the work of film scholar Gaylyn Studlar might help explicate this sense of being entranced to the point of compulsive repetition. In her response to Laura Mulvey's influential work on the controlling, sadistic nature of the male gaze, Studlar, via Gilles Deleuze, argues that there are significant overlaps between "the formal structures of the masochistic aesthetic [and the] primary structures that enable cinema to produce visual pleasure," and that "masochistic repetition sustains the paradoxical pain/pleasure structure of the perversion's psychodynamics and reflects the careful control of desire so necessary to sustaining the masochistic scenario." 2 Especially useful, then, is the sense of masochistic submission, not mastery, through the gaze; it is crucial to the ineffable power the video holds over me, in large part because of its montage form and the almost paradoxical tension between its legibility and fathomlessness, with this sensation being reinforced by repeated viewings.

Todd McGowan, drawing on Lacan, goes further, arguing that the gaze represents "the site of a traumatic encounter with the Real, with the utter failure of the spectator's seemingly safe distance and assumed mastery," and that it contains within itself the Lacanian remainder, reciprocated by the Other yet ultimately unable to be seen or captured by the subject. $\underline{3}$ Taking these ideas to their hyperbolic conclusion, then, there is a resonance with Macon Holt's interpretation of the eponymous film in David Foster Wallace's Infinite Jest: that the characters' compulsive, insatiable, watching of the film is borne from a desire to return to an (unreachable) state of pre-subjective bliss, and they become trapped in an ultimately fatal hedonic catatonia as a result. ${ }^{4}$ I mean, isn't that what we all want?

\section{Bibliography}

Holt, Macon. Pop Music and Hip Ennui: A Sonic Fiction of Capitalist Realism. New York, NY: Bloomsbury Academic, 2019.

McGowan, Todd. "Looking for the Gaze: Lacanian Film Theory and Its Vicissitudes." Cinema Journal 42, no. 3 (2003): 27-47.

Mulvey, Laura. “Visual Pleasure and Narrative Cinema." Screen 16, no. 3 (October 1975): 6-18. https://doi.org/10.1093/screen/16.3.6.

Studlar, Gaylyn. "Masochism and the Perverse Pleasures of the Cinema." Quarterly Review of Film Studies 9, no. 4 (September 1984): 267-82. https://doi.org/10.1080/10509208409361219. 


\section{Media Cited}

Oneohtrix Point Never. “Oneohtrix Point Never - Lost But Never Alone (Official Video)." YouTube video, 4:24. November 12, 2020. https://www.youtube.com/watch?v=6iKPkxfljBY.

\section{Footnotes}

1. Oneohtrix Point Never, "Oneohtrix Point Never - Lost But Never Alone (Official Video)," November 12, 2020, https://www.youtube.com/watch?v=6iKPkxfljBY. $\subseteq$

2.

Laura Mulvey, “Visual Pleasure and Narrative Cinema," Screen 16, no. 3 (1 October 1975): 6-18, https://doi.org/10.1093/screen/16.3.6;

Gaylyn Studlar, "Masochism and the Perverse Pleasures of the Cinema," Quarterly Review of Film Studies 9, no. 4 (September 1984): 268-72, https://doi.org/10.1080/10509208409361219.

3. Todd McGowan, "Looking for the Gaze: Lacanian Film Theory and Its Vicissitudes," Cinema Journal 42 , no. 3 (2003): 29-33.

4. Macon Holt, Pop Music and Hip Ennui: A Sonic Fiction of Capitalist Realism (New York, NY: Bloomsbury Academic, 2019), 124. 